\title{
Personality Traits Predict Treatment Outcome in Alcohol-Dependent Patients
}

\author{
Sandra E. Müller ${ }^{a}$ Heinz-Gerd Weijers ${ }^{b}$ Jobst Böning ${ }^{c} \quad$ Gerhard A. Wiesbeck $^{a}$

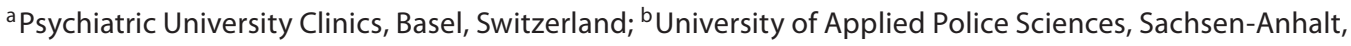 \\ Aschersleben, and ${ }^{C}$ Department of Psychiatry, University of Würzburg, Würzburg, Germany
}

\section{Key Words}

Alcoholism - Personality traits - Treatment outcome, relapse

\begin{abstract}
Personality traits are important individual characteristics modifying responses to therapy in various diseases. The aim of this study was to identify personality traits that may predict treatment outcome in alcohol-dependent patients. The present analysis was based on a total of 146 alcohol-dependent patients (109 male, 37 female) after detoxification. The variable of interest was treatment outcome (abstinence/relapse) after a 1-year follow-up. To identify personality traits as predictors of treatment outcome, 5 personality questionnaires (NEO 5-Factor Inventory, Temperament and Character Inventory, Eysenck Personality Questionnaire, Eysenck Impulsiveness-Venturesomeness-Empathy Scale and Sensation-Seeking Scale) were applied. Data analysis was performed by using a classification and regression tree analysis (CART; a nonparametric technique for data with a complex structure) in order to find a decision rule to predict treatment outcome from personality traits. The CART model identified psychoticism and persistence as the 2 most relevant discriminatory parameters, of which psychoticism was used as the first node in the model, classifying $64 \%$ of the patients correctly as relapsed and $12 \%$ correctly as abstinent. In addition, the risk of relapse was even higher in patients
\end{abstract}

\section{KARGER}

Fax +41613061234

E-Mail karger@karger.ch

www.karger.com (c) 2008 S. Karger AG, Basel

$0302-282 X / 08 / 0574-0159 \$ 24.50 / 0$

Accessible online at:

www.karger.com/nps with a substantial score in psychoticism and a low score in persistence. When comparing relapsed and abstinent patients, further variables, such as scores for novelty seeking (20.9 \pm 5.5 vs. $18.5 \pm 5.9$ ) and impulsiveness ( $8.4 \pm 3$ vs. 7.2 $\pm 3.5)$, showed significance. In addition, relapsed patients lived alone more often than abstinent patients (52 vs. $25 \%$, $p=0.004)$. In conclusion, this analysis demonstrated that specific personality characteristics, namely psychoticism and persistence, are usable predictors for the risk of relapse in alcohol-dependent patients. Copyright $\odot 2008$ S. Karger AG, Basel

\section{Introduction}

Though psychosocial treatment programs for alcohol dependence have been successful, the effect is only moderate if they aim at abstinence $[1,2]$. In alcoholism, relapses are seen as a part of the recovery process. Relapse rates are high, reaching more than $50 \%$ within 1 year after treatment $[3,4]$. If specific factors altering the outcome could be identified, treatment programs could be optimized and patients allocated to highly adjusted treatment programs.

Personality traits build the basis of consistent patterns of experience and behavior, which in turn have been found to predict the outcome of treatment in different diseases. For example, personality traits emerged as use- 
ful predictors of treatment outcome in patients with gastrointestinal disorders [5], obesity [6], hyperopia [7] and even individual responses to certain surgical treatments seem to be associated with personality $[8,9]$. In psychiatry, personality traits have been successfully linked to treatment outcome in depression [10], anorexia nervosa $[11,12]$, schizophrenia [13] and withdrawal severity in benzodiazepine dependence [14]. In alcoholism research, personality traits have become a matter of scientific interest as well [15-20]. Regarding treatment outcome, several authors identified specific personality traits as predictors of relapse in alcohol dependent patients [21, 22]. For example, the personality trait 'novelty seeking' is a strong predictor of relapse in detoxified male alcoholics, whereas the trait 'harm avoidance' has been shown to predict early relapse in females [21]. This is in line with results of Kravitz et al. [23], which revealed that dropouts in a study of alcohol-dependent men had higher novelty-seeking scores than non-dropouts. The risk of relapse, 1 year after an inpatient treatment program for alcohol-dependent patients, is greatest in patients with low scores in conscientiousness and high scores in neuroticism [22, 24]. In addition, several follow-up studies over 6 months revealed low persistence scores as predictors of relapse in alcohol-dependent patients [25-27].

In conclusion, the evidence suggests that personality traits are important individual factors influencing treatment outcome, not only in various diseases, but also in alcoholism. Therefore, the present study was performed to identify predictors of treatment outcome in primary alcohol-dependent patients on the basis of personality traits.

\section{Methods}

All patients in this analysis were recruited from an alcohol inpatient treatment program at the Department of Psychiatry at the University of Würzburg in Germany. A total of 176 patients (130 male, 46 female) had to fulfill the ICD-10 criteria of alcohol dependence. The diagnosis was established by using the Semi-Structured Assessment for the Genetics of Alcoholism [28], which consists of a personal interview designed to study in detail alcoholism associated with comorbid psychiatric diagnoses of current and lifetime status. Exclusion criteria were psychiatric comorbidity, personality disorders, severe neurological or medical disorders, and a history of illegal drug use.

\section{Procedure}

All patients attended an inpatient psychosocial treatment program, including detoxification and a motivational counseling session for abstinence for 6 weeks. Once a week, patients had to complete 5 different personality questionnaires during a morning session not exceeding $1 \mathrm{~h}$. At this time, all patients were detoxified, without any symptoms of withdrawal and without any psychoactive medication. The 5 questionnaires were self-reporting scales, and were always completed in the same order of sequence. To measure personality dimensions according to the 5 -factor model of Costa and McCrae [29], the German version of the NEO 5 -Factor Inventory (NEO-FFI) [30] was used. The NEO-FFI consists of 5 personality dimensions, namely: neuroticism, extraversion, openness to experience, agreeableness and conscientiousness. To assess temperament and character traits, the Temperament and Character Inventory (TCI) of Cloninger et al. [31] was applied. The TCI distinguishes 4 temperament dimensions that are stable over time, namely: novelty seeking (curiosity), harm avoidance, reward dependence and persistence (insistency), and 3 character dimensions: self-directedness, cooperativeness and self-transcendence. The Eysenck Personality Questionnaire (EPQ) assesses 3 personality dimensions: psychoticism, extraversion and neuroticism. The construct of psychoticism assesses subjects who are aggressive, cold, egocentric, impersonal, not empathic and tough-minded [32]. In addition, the 'lie' scale of the EPQ identifies socially conforming answers. As a further instrument, the Eysenck Impulsiveness-Venturesomeness-Empathy Scale (I7), with 3 independent scores measuring impulsiveness (poor behavioral control and lack of ability to delay gratification), venturesomeness and empathy, was administered. Furthermore, the Sensation-Seeking Scale (SSS) of Zuckerman, which consists of 4 scales (thrill and adventures seeking, experience seeking, disinhibition and boredom susceptibility) [17,33], was applied.

Twelve months after treatment discharge, follow-up information about patients' abstinence was collected using different sources of information. The primary source of information was, whenever possible, a personal interview either face-to-face or conducted by phone (using the standards for documentation of alcohol anamneses from the German Society for Addiction Research and Therapy [34]). A further source was information gathered from spouses, life-partners, relatives, roommates, neighbors and friends of the patients. Other sources such as clinical briefs, reports from physicians or hospitals, and workers of the addiction therapy system were collected if available. Patients were only classified as relapsed or abstinent if at least 2 corresponding and yet independent sources of follow-up information were available. If patients started to drink again, even for only 1 day, they were classified as relapsed. Only patients who drank no alcohol during the follow-up period were classified as abstinent.

\section{Data Analysis}

In a first step, all characteristics of abstinent and relapsed patients were compared using a 1-way ANOVA to investigate whether there were differences between the groups. Thereafter, a discriminate analysis technique was performed to detect the most essential predictors among those personality variables that differed between abstinent and relapsed patients. Since there are well-known gender differences in personality scores [21], the calculation for the prediction model was made first for men and then for women. In a last step, the classification and regression tree analysis (CART) was applied to find a reliable clinical decision rule $[35,36]$. CART is a tree-based approach to determine the category of relapse risk an individual falls into when using personality scores as predictors. Compared to a multivariate logistic regression, the CART analysis has the advantage of including an 
Table 1. Comparison of demographic characteristics in relapsed and abstinent patients

Total Abstinent Relapsed p

$(\mathrm{n}=176) \quad(\mathrm{n}=65) \quad(\mathrm{n}=81) \quad$ value

\begin{tabular}{lrrrr}
\hline Gender & & & & \\
Women & 46 & 18 & 19 & 0.559 \\
Men & 130 & 47 & 62 & \\
\hline Age, years & & & & \\
Mean & 41.3 & 41.0 & 41.2 & \\
SD & 8.3 & 9.0 & 7.6 & 0.868 \\
Range & $18-61$ & $18-58$ & $23-61$ & \\
\hline
\end{tabular}

Family status

Married

Single

Widowed

$84 \quad 40 \quad 30$

$3-1-14$

0.007

Divorced/separated $\quad 54 \quad 10 \quad 36$

\begin{tabular}{lrrrr}
\hline Living situation & & & & \\
Living alone & 70 & 16 & 42 & 0.004 \\
Living together with a partner & 106 & 49 & 39 & \\
\hline
\end{tabular}

Graduation

$\begin{array}{llll}\text { Without graduation } & 3 & 1 & 0\end{array}$

Elementary school $\quad 103 \quad 36 \quad 50$

Junior high school $\quad 44 \quad 17 \quad 19$

High school $\quad 15 \quad 5 \quad 8$

$\begin{array}{llll}\text { University } & 11 & 6 & 4\end{array}$

Occupational status

$\begin{array}{llll}\text { Employed } & 96 & 41 & 37\end{array}$

$\begin{array}{llll}\text { Unemployed } & 59 & 13 & 35\end{array}$

Housewife/houseman $\quad 10 \quad 3 \quad 6$

Pupil/student/practical training $\begin{array}{llll}4 & 3 & 0\end{array}$

Retired

$\begin{array}{lll}1 & 1 & 0\end{array}$

unlimited number of independent variables or predictors, which are free of the level of measurement and distribution. CART is based on an exhaustive search trying all possible variables as splitters. Under these conditions the result of a decision rule is relatively simple to interpret and feasible for clinical use. Due to the low number of female patients in the present sample, no gender-specific calculations were made. All statistical analyses were calculated using Statistica for Windows version 6.0.

\section{Results}

\section{Patient Characteristics}

One year after treatment discharge, 146 patients of the total of 176 could be classified as relapsed or abstinent on the basis of 2 concurring information sources. Thus, 81 patients were classified as relapsed, while 65 patients were classified as abstinent. Thirty patients could not reliably be classified. The evaluation of demographic characteristics 1 year after treatment revealed considerable differences in the subjects' living situations and family statuses. On the one hand, relapsed patients showed no differences in their living situations (living alone vs. living with someone), although they were less frequently married $[37 \%(\mathrm{n}=30)]$, and therefore more often single, divorced or separated $[63 \%(n=51)]$. On the other hand, patients who stayed abstinent were more often living together with someone $[75.4 \%(n=49)]$ than alone $[24.6 \%$ $(\mathrm{n}=16)]$, and were more often married or in a relationship $[61.5 \%(n=40)]$ than alone $[38.5 \%(n=25)]$. No differences were found in gender, age, school education or occupational status when comparing relapsed versus abstinent participants (table 1).

Autobiographical and alcohol-specific characteristics, such as age of alcoholism onset, duration of alcohol dependence, alcohol intake before detoxification and positive versus negative family history of alcoholism, did not reveal significance. Furthermore, biological markers such as glutamyltransferase and mean corpuscular volume did not differ significantly between relapsed and abstinent patients.

\section{Personality Traits and Treatment Outcome}

Data on personality differences between relapsed and abstinent subjects are summarized in table 2. The most conspicuous difference was the psychoticism score in the EPQ showing a significantly higher score in relapsed than in abstinent patients $(\mathrm{p}=0.001)$. Furthermore, relapsed patients scored significantly lower on the persistence scale of Cloninger et al. [31] in the TCI than abstinent patients $(\mathrm{p}=0.022)$. Moreover, relapsed patients scored significantly higher on the novelty-seeking scale (TCI; $\mathrm{p}=0.028)$ and impulsiveness scale (I7; $\mathrm{p}=0.046)$ than abstinent patients. However, scales of the NEO-FFI and SSS did not reveal any significant differences. Taken together, relapsed patients showed higher scores in psychoticism, novelty seeking and impulsiveness, but lower scores in persistence, when compared to abstinent patients.

The stepwise discriminate analysis detected a significant model with 2 important predictors, namely psychoticism and persistence $\left(\chi^{2}=14.8\right.$, d.f. $\left.=2, p<0.1, R=0.41\right)$. These 2 parameters were the most discriminate variables that correctly predicted relapse in $62 \%$ and abstinence in $73 \%$ of the patients $(\mathrm{D}=0.848 \times \mathrm{EPQ}$-psychoticism $-0.582 \times$ TCI-persistence). In the next step of data analysis, CART was used to establish a classification rule for 
Table 2. Measures (mean \pm SD) of personality traits in abstinent and relapsed patients

\begin{tabular}{|c|c|c|c|}
\hline & $\begin{array}{l}\text { Abstinent } \\
(\mathrm{n}=65)\end{array}$ & $\begin{array}{l}\text { Relapsed } \\
(\mathrm{n}=81)\end{array}$ & $\mathrm{p}$ value \\
\hline \multicolumn{4}{|l|}{ TCI } \\
\hline Harm avoidance & $17.2 \pm 6.4$ & $16.3 \pm 7.1$ & 0.487 \\
\hline Novelty seeking & $18.5 \pm 5.9$ & $20.9 \pm 5.5$ & 0.028 \\
\hline Reward dependence & $14.2 \pm 3.6$ & $13.9 \pm 4.1$ & 0.760 \\
\hline Persistence & $4.6 \pm 1.8$ & $3.8 \pm 1.8$ & 0.022 \\
\hline Self-directedness & $30.9 \pm 5.8$ & $30.5 \pm 6.7$ & 0.704 \\
\hline Cooperativeness & $32.1 \pm 4.9$ & $31.1 \pm 5.7$ & 0.316 \\
\hline Self-transcendence & $13.5 \pm 6.8$ & $11.9 \pm 6.3$ & 0.199 \\
\hline \multicolumn{4}{|l|}{ NEO-FFI } \\
\hline Neuroticism & $1.9 \pm 0.6$ & $1.9 \pm 0.6$ & 0.845 \\
\hline Extraversion & $2.1 \pm 0.5$ & $2.3 \pm 0.4$ & 0.186 \\
\hline Openness to experience & $2.3 \pm 0.4$ & $2.3 \pm 0.5$ & 0.771 \\
\hline Agreeableness & $2.5 \pm 0.4$ & $2.4 \pm 0.4$ & 0.328 \\
\hline Conscientiousness & $2.8 \pm 0.4$ & $2.6 \pm 0.6$ & 0.055 \\
\hline \multicolumn{4}{|l|}{$E P Q$} \\
\hline Neuroticism & $5.8 \pm 3.1$ & $6.0 \pm 3.0$ & 0.705 \\
\hline Extraversion & $6.0 \pm 3.7$ & $6.4 \pm 3.2$ & 0.520 \\
\hline Psychoticism & $1.4 \pm 1.4$ & $2.4 \pm 1.7$ & 0.001 \\
\hline Lie scale & $3.2 \pm 2.4$ & $3.0 \pm 1.9$ & 0.582 \\
\hline \multicolumn{4}{|l|}{ I7 } \\
\hline Impulsiveness & $7.2 \pm 3.5$ & $8.4 \pm 3.0$ & 0.046 \\
\hline Venturesomeness & $7.7 \pm 4.0$ & $8.0 \pm 3.4$ & 0.645 \\
\hline Empathy & $9.4 \pm 3.2$ & $8.9 \pm 3.6$ & 0.412 \\
\hline \multicolumn{4}{|l|}{ SSS } \\
\hline Sensation seeking (total) & $15.3 \pm 5.7$ & $17.1 \pm 5.2$ & 0.086 \\
\hline Thrill and adventure seeking & $4.2 \pm 3.1$ & $4.7 \pm 3.2$ & 0.397 \\
\hline Experience seeking & $4.5 \pm 1.5$ & $5.0 \pm 1.5$ & 0.073 \\
\hline Disinhibition & $3.0 \pm 1.9$ & $3.2 \pm 1.7$ & 0.492 \\
\hline Boredom susceptibility & $3.6 \pm 2.3$ & $4.1 \pm 2.1$ & 0.291 \\
\hline
\end{tabular}

clinical practice to determine the relapse risk for an individual on the basis of his psychoticism and persistence scores. Due to the low number of female patients in the present sample, significant gender-specific differences could not be found. Splitting the male sample into 2 subpopulations using a psychoticism cutoff score of 0.37 discriminated the groups well. Only 5 out of 24 (21\%) of the patients with a psychoticism score less than 0.37 relapsed within 1 year after discharge, compared to 54 out of 85 (64\%) with a score above 0.37 . When, in the next step, the sample was split according to the persistence score with a cutoff of 3.5, more than two-thirds of patients (25/32) with a psychoticism score above 0.37 and a persistence score of less than 3.5 relapsed during the 1-year followup.

\section{Discussion}

The main finding of the present analysis was that specific personality traits seem to contribute to the risk of relapse after detoxification in primary alcohol-dependent patients. Besides these personality traits, demographic variables, namely living alone and being divorced or separated, displayed a risk of relapse in primary alcohol-dependent persons. Four specific personality traits could be identified, which distinguished between relapsed and abstinent patients 1 year after treatment discharge. Results showed that relapsed patients have higher scores in psychoticism, novelty seeking and impulsiveness, and lower scores in persistence than abstinent patients.

The tree-based predictive model revealed the classification rule that patients with substantial scores in psychoticism and low values in persistence are at high risk of relapse. Interestingly, the cutoff in psychoticism was very low, with a value of 0.37 (range $0-7$ ), indicating that most of the patients with scores below the cutoff had negligible values on all psychoticism items. This classification rule of high scores in psychoticism and low scores in persistence was determined only for the male sample and should be interpreted with caution for women. Persons with high scores in psychoticism are characterized as uninhibited, impulsive, hostile and aggressive. It is a wellknown fact that psychoticism and impulsiveness are highly correlated [32], in particular psychoticism and dysfunctional impulsiveness [37]; however, since impulsiveness and novelty seeking [38], as well as novelty seeking and sensation seeking [39], also share a large part of variance (due to the fact that all of them contain aspects of extraversion), it is not surprising that novelty seeking is also associated with relapse in alcoholics. Although the scores of sensation seeking did not reach significance in the present analysis, a tendency towards higher values in relapsed patients could be seen, confirming published data on elevated novelty-seeking scores in relapsed alcohol-detoxified patients [21, 23].

Individuals with high scores in persistence are described as industrious, hard-working and stable, despite frustration and fatigue. They are characterized as ambitious overachievers who are willing to make major sacrifices in order to succeed. In contrast, those with low persistence rarely intensify their effort, even in response to anticipated reward, and tend to give up easily when faced with frustration, criticism, obstacles and fatigue. There appears to be considerable face validity to the notion that low persistence predicts relapse. The present finding that 
a low persistence score has a predictive value for relapse in the disorder of alcoholism confirms published reports [25-27].

The well-documented personality traits in relapsed patients with high scores in neuroticism and low scores in conscientiousness $[22,24]$ measured by the NEO-FFI could not be confirmed unequivocally in the present analysis. However, there was a trend towards lower scores in conscientiousness in relapsed patients $(\mathrm{p}=$ $0.055)$.
A future goal in alcoholism research should be to elucidate psychobiological correlates of personality characteristics that are related to relapse and could be used for optimizing treatment.

\section{Acknowledgment}

This study was supported by grant 01EB9410 from the German Bundesministerium für Bildung und Forschung.

\section{References}

1 Bottlender M, Kohler J, Soyka M: The effectiveness of psychosocial treatment approaches for alcohol dependence - a review (in German). Fortschr Neurol Psychiatr 2006;74 19-31.

2 Miller WR, Wilbourne PL, Hettema JE: What works? A summary of alcohol treatment outcome research; in Hester RK, Miller WR (eds): Handbook of Alcoholism Treatment Approaches. Boston, Allyn and Bacon, 2003, pp 13-63.

3 Suess HM: The effectiveness of the treatment for alcoholics: results of a meta-analysis (in German). Psychologische Rundschau 1995; 46:248-266.

4 Mueller SE, Petitjean S, Boening J, Wiesbeck GA: The impact of self-help group attendance on relapse rates after alcohol detoxification in a controlled study. Alcohol Alcohol 2007;42:108-112.

5 Tanum L, Malt UF: Personality traits predict treatment outcome with an antidepressant in patients with functional gastrointestinal disorder. Scand J Gastroenterol 2000;35: 935-941.

-6 Jonsson B, Bjorvell H, Levander S, Rossner S: Personality traits predicting weight loss outcome in obese patients. Acta Psychiatr Scand 1986;74:384-387.

7 Uretmen O, Kesikci H, Erermis S, Kose S, Pamukcu K, Aydin C: Could personality traits modify the response to uncorrected high hyperopia? J Aapos 2005;9:480-484.

$\checkmark 8$ Radl R, Leithner A, Zacherl M, Lackner U, Egger J, Windhager R: The influence of personality traits on the subjective outcome of operative hallux valgus correction. Int Orthop 2004;28:303-306.

$>9$ Bull RH, Legorreta G: Outcome of gastric surgery for morbid obesity: weight changes and personality traits. Psychother Psychosom 1991;56:146-156.

10 O'Leary D, Costello F: Personality and outcome in depression: an 18-month prospective follow-up study. J Affect Disord 2001;63: 67-78.
Bulik CM, Tozzi F, Anderson C, Mazzeo SE, Aggen S, Sullivan PF: The relation between eating disorders and components of perfectionism. Am J Psychiatry 2003;160:366368.

12 Casper RC: Personality features of women with good outcome from restricting anorexia nervosa. Psychosom Med 1990;52:156170 .

13 Wickett A, Essman W, Beck-Jennings J, Davis L, McIlvried J, Lysaker PH: Cluster B and C personality traits, symptom correlates, and treatment utilization in postacute schizophrenia. J Nerv Ment Dis 2006;194: 650-653.

14 Schweizer E, Rickels K, De Martinis N, Case G, Garcia-Espana F: The effect of personality on withdrawal severity and taper outcome in benzodiazepine dependent patients. Psychol Med 1998;28:713-720.

15 Wiesbeck GA, Weijers HG, Wodarz N, Keller HK, Michel TM, Herrmann MJ, Boening J: Serotonin transporter gene polymorphism and personality traits in primary alcohol dependence. World J Biol Psychiatry 2004;5: 45-48.

16 Weijers HG, Wiesbeck GA, Boning J: Temperament- and character traits as well as trait patterns in alcoholic men and controls (in German). Nervenarzt 1999;70:998-1008

17 Weijers HG, Wiesbeck GA, Jakob F, Boning $\mathrm{J}$ : Neuroendocrine responses to fenfluramine and its relationship to personality in alcoholism. J Neural Transm 2001;108:10931105.

18 Weijers HG, Wiesbeck GA, Wodarz N, Keller $\mathrm{H}$, Michel T, Boning J: Gender and personality in alcoholism. Arch Womens Ment Health 2003;6:245-252.

19 Thome J, Weijers HG, Wiesbeck GA, Sian J, Nara K, Boning J, Riederer P: Dopamine $\mathrm{D}_{3}$ receptor gene polymorphism and alcohol dependence: relation to personality rating. Psychiatr Genet 1999;9:17-21.
20 Fallgatter AJ, Wiesbeck GA, Weijers HG, Boening J, Strik WK: Event-related correlates of response suppression as indicators of novelty seeking in alcoholics. Alcohol Alcohol 1998;33:475-481.

21 Meszaros K, Lenzinger E, Hornik K, Fureder T, Willinger U, Fischer G, Schonbeck G, Aschauer HN: The Tridimensional Personality Questionnaire as a predictor of relapse in detoxified alcohol dependents: The European Fluvoxamine in Alcoholism Study Group. Alcohol Clin Exp Res 1999;23:483486.

22 Bottlender M, Soyka M: Impact of different personality dimensions (NEO Five-Factor Inventory) on the outcome of alcohol-dependent patients 6 and 12 months after treatment. Psychiatry Res 2005;136:61-67.

23 Kravitz HM, Fawcett J, McGuire M, Kravitz GS, Whitney M: Treatment attrition among alcohol-dependent men: is it related to novelty seeking personality traits? J Clin Psychopharmacol 1999;19:51-56.

24 Fisher LA, Elias JW, Ritz K: Predicting relapse to substance abuse as a function of personality dimensions. Alcohol Clin Exp Res 1998;22:1041-1047.

25 Sellman JD, Mulder RT, Sullivan PF, Joyce $\mathrm{PR}$ : Low persistence predicts relapse in alcohol dependence following treatment. J Stud Alcohol 1997;58:257-263.

26 Janowsky DS, Boone A, Morter S, Howe L: Personality and alcohol/substance-use disorder patient relapse and attendance at selfhelp group meetings. Alcohol Alcohol 1999; 34:359-369.

27 Cannon DS, Keefe CK, Clark LA: Persistence predicts latency to relapse following inpatient treatment for alcohol dependence. Addict Behav 1997;22:535-543.

28 Bucholz KK, Cadoret R, Cloninger CR, Dinwiddie SH, Hesselbrock VM, Nurnberger JI Jr, Reich T, Schmidt I, Schuckit MA: A new, semi-structured psychiatric interview for use in genetic linkage studies: a report on the reliability of the SSAGA. J Stud Alcohol 1994;55:149-158. 
29 Costa P, McCrae R: The NEO PI/FFI Manual Supplement. Odessa, Psychological Assessment Resources, 1989.

30 Borkenau T, Ostendorf F: NEO-Fünf-Faktoren Inventar (NEO-FFI). Göttingen, Hogrefe, 1993.

31 Cloninger CR, Przybeck TR, Svaric DM, Wentzel RD: The Temperament and Character Inventory (TCI): A guide to its development and use. St. Louis, Washington University, 1994.
32 Ruch W: The Eysenck Personality Questionnaire-Revised and the Construction of German Standard and Short Versions (EPQ-R and EPQ-RK). Z Differ Diagn Psychol 1999; 20:1-24.

-33 Weijers HG, Wiesbeck GA, Wodarz N, Keller $\mathrm{H}$, Michel T, Boning J: Gender and personality in alcoholism. Arch Womens Ment Health 2003;6:245-252.

34 Deutsche Gesellschaft für Suchtforschung und Suchttherapie: Dokumentationsstandards 2 für die Behandlung von Abhängigen. Freiburg, Lambertus, 1992.

35 Steinberg D, Colla P: CART - Classification and Regression Trees. San Diego, Salford Systems, 1997
36 Breiman L, Friedman J, Olshen R, Stone C: Classification and Regression Trees. Pacific Grove, Wadsworth, 1984.

37 Heaven PCL: Personality correlates of functional and dysfunctional impulsiveness. Person Individ Diff 1991;12:1213-1217.

38 Wills TA, Vaccaro D, McNamara G: Novelty seeking, risk taking, and related constructs as predictors of adolescent substance use: an application of Cloninger's theory. J Subst Abuse 1994;6:1-20.

39 McCourt WF, Gurrera RJ, Cutter HS: Sensation seeking and novelty seeking: are they the same? J Nerv Ment Dis 1993;181:309312 . 